\title{
Technology and Studies for Greenhouse Cooling
}

\author{
Hugang Li, Shuangxi Wang* \\ Engineering College, Shanxi Agricultural University, Taigu, China \\ Email: 1454051740@qq.com, sxauwsx@126.com
}

Received 10 August 2015; accepted 22 August 2015; published 25 August 2015

\begin{abstract}
Greenhouse technology is an efficient and viable option, especially for the sustainable crop production in the regions of adverse climatic conditions. High summer temperature is one of the worst effects on greenhouse crop production throughout the year. The main purpose of this paper is to present some technologies and studies for greenhouse cooling in summer. In the paper, some applicable and practical cooling technologies have been discussed. The choice of efficient cooling method depends on many aspects, such as local climate, agronomic condition, design and covering materials. To achieve desirable benefits, the combination of different cooling methods is necessarily used. Analysis of earlier studies revealed that a naturally ventilated greenhouse with larger ventilation areas $(15 \%-30 \%)$, provided at the ridge and side covered with insect-proof nets of 20 - 40 mesh size with covering material properties of NIR (near infrared radiation) reflection during the day and FIR (far infrared radiation) reflection during night was suitable for greenhouse production throughout year in some special regions. Evaporation cooling is the most effective cooling method for controlling the temperature and humidity inside a greenhouse. However, its suitability is restricted to the respective region and climate when the humidity level is high. The entry of un- wanted radiation or light can be controlled by the use of shading. Researches show that shade net application with different perforated mesh size and their evaluation with respect to local climate and region are necessary to get cooling benefits in summer.
\end{abstract}

\section{Keywords}

Greenhouse Cooling Technologies and Studies, Natural Ventilation, Evaporation Cooling, Shading

\section{Introduction}

Greenhouse technology is a breakthrough in the agriculture production technology, it integrates market driven quality parameters with production system profits. Although greenhouse protects crops from external bad weather, high temperature and humidity during summer months cause adverse effect on crop production. Thus, in such regions, reduction of air temperature inside the greenhouse or the regulation of temperature close to the ambient temperature during summer is necessary for successful crop production.

Cooling is considered as the basic necessity for greenhouse crop production to overcome the problems of high temperature during summer months. Development of suitable cooling system that provides optimized micro 
climate for crop growth is a difficult task as the design is closely related to the local environmental condition. Besides, the selection of appropriate technology for cooling depends on the crop to be grown, maintenance, ease of operation and economic viability [1]. Hence, understanding of greenhouse, its size, shape, covering material and external weather helps in the development of suitable cooling system. Evaluating micro climate in different designs of the greenhouse and establishing physical and physiological relationship of crops is necessary for greenhouse designers to improve cooling system that is suitable for crop growth.

Earlier studies on greenhouse cooling revealed that the present techniques used for cooling were not satisfactory. There is a necessity to find suitable cooling method for greenhouse cooling in peak summer. Thus, development of applicable cooling technologies is an important research endeavor. And appropriate greenhouse design (shape, size and roof configuration), right choice of cladding material coupled with suitable ventilation and cooling techniques address the problems of summer greenhouse production of high temperature regions. So, there is a necessity to carry out in deep investigation on the design aspects of greenhouse and its functional characteristics influence on micro climate. Established cooling technologies like natural ventilation, evaporation cooling, shading and composite systems and their application implications have been discussed with a note in greenhouse technologies. And the information is useful for the researchers' work on the engineering aspects of greenhouse technology.

\section{Greenhouse Cooling Technologies}

\subsection{Natural Ventilation}

Natural ventilation is the cheapest method of cooling a greenhouse. And its driven force is the pressure differences, which is created and maintained by wind or temperature gradients. It depends on the crop. In this section, research on greenhouse natural ventilation application to high temperature climate in summer has been reviewed and presented in detail. Wang Shuangxi and Wang Xu [2] carried out the experimental studies in plastic covered muti-span greenhouse. In north china, they investigate the ventilation rate for the performances of various vents in it. And found that the colling-up vent had a higher ventilation rate (up to 2.32 times) than the continuous roof one. The better ventilation ( more than $60 \%$ at the wind speed of $3.0 \mathrm{~m} / \mathrm{s}$ ) could be achieved with vents near the ridge of the roof instead of near the gutter, and the obvious reduction $(18 \%-22 \%$ at the wind speed of $3.0 \mathrm{~m} / \mathrm{s})$ in the rate values when an insect-proof screen was fitted to it. Teitel and Tanny [3] carried out theoretical and experimental studies in a four-span greenhouse of $960 \mathrm{~m}^{2}$, floor area in the south of Isreal.

Continuous vertical roof windows resulted in the decrease of air temperature and humidity ratio with time and approached to a steady state. Teitel et al. [4] studied the effect of continuous screened side vents on the ventilation rate, temperature, humidity and air velocity distributions in a naturally ventilated greenhouse. Results indicated that the ventilation rate increased linearly with wind speed. The temperature and humidity ratios were larger near the roof than near the crop while the air velocity was higher near the crop than near the roof. Teitel et al. [5] investigated the air flow patterns and air temperature distributions in a naturally ventilation greenhouse with vertical roof openings using computational fluid dynamics technique. The results show significant effect of the flow patterns, both inside and at the roof openings. Wind direction, significantly affected the ventilation rate, airflow and crop temperature distributions. Measured ventilation rates are in reasonable agreement with estimated ventilation rates predicted by a model. However, air velocities at the greenhouse openings differed from the measured values. Impron et al. [6] developed a simple model to predict the micro climate of greenhouse appropriately, optimizing the cover properties and ventilation as main parameters for a naturally ventilated greenhouse under tropical low lands of Indonesia. The measured and predicted values are in good agreement.

From the available review on natural ventilation as means of cooling, it can be concluded that wind and buoyancy effect are the main controlling agents for getting a favorable micro climate and air exchange rate in tropics and subtropics. Buoyancy effect cannot be neglected completely, though its effect on natural ventilation is not prominent when external wind speed exceeds $2-2.5 \mathrm{~m} / \mathrm{s}$. Relative larger ventilation openings provided at the roof and ridge can realize acceptable natural ventilation cooling in tropical and subtropical regions.

\subsection{Evaporation Cooling}

Evaporation cooling is the most effective cooling method for controlling the temperature and humidity inside a greenhouse. However, its suitability is restricted to the respective region and climate as humid tropics seldom 
suits for its application due to high humidity levels.

\subsubsection{Fan-Pad System}

Kozai and Sase [7] and Landsberg et al [8] studied the efficiency of fan-pad system in subtropical region. They reported that for a freely transpiring crop in the glasshouse, inside air temperatures can be reduced by $8{ }^{\circ} \mathrm{C}-12^{\circ} \mathrm{C}$ under high ambient temperatures and radiation intensities. Chandra et al. [9] conducted an experimental study in a $24 \mathrm{~m}^{2}$ plastic covered greenhouse using negative pressure fan and pad system for cooling. Landsberge's model was used to predict air temperature inside greenhouse. Decrease in inside air temperature to a range of $4^{\circ} \mathrm{C}-5^{\circ} \mathrm{C}$ compared to outside condition was achieved. Jain and Tiwari [10] conducted theoretical experimental studies of fan-pad evaporation cooling system in a $24 \mathrm{~m}^{2}$ greenhouse. They reported that the greenhouse air temperature was lowered by $4^{\circ} \mathrm{C}-5^{\circ} \mathrm{C}$ against ambient condition by using fan and pad system. The results of the parametric studies to optimize the fan-pad cooling parameters revealed that length of greenhouse and height of the cooling pad were found sensitive to cooling. Ahmed et al. [11] conducted experimental studies of three different types of local evaporation cooling pads on effective growth factors, such as temperature, relative humidity, the results obtained for crop parameters showed that there were significant differences between all parameters inside the greenhouses; however, the greenhouses with sliced wood pads gave the highest yield and the greenhouses with straw pads gave the least and conditions outside gave the lowest. This study indicated that the sliced wood pads are better than the other evaporation cooling pads.

\subsubsection{Fog/Mist System}

This system is based on spraving water a small droplets (droplet diameter of 2 - $60 \mu \mathrm{m}$ ) with high pressure nozzles. Cooling is achieved by evaporation of droplet. Meanwhile, fogging can also be used to increase the relative humidity apart from cooling the greenhouse.

Montero et al. [12] used an air water fogging system to cool the greenhouse with shade screen of $45 \%$ perforations. It was reported that maximum temperature reduction during sunny days was $5^{\circ} \mathrm{C}$. Arbel et al. [13] tested the efficiency of the fog system with a droplet size of $2-60 \mu \mathrm{m}$ in $16 \mathrm{~m} \times 24 \mathrm{~m}$ greenhouse under Isreal climatic conditions. The results were compared with fan and pad system. They concluded that performance of fog system was better than fan-pad system as temperature and relative humidity variation were $<5^{\circ} \mathrm{C}$ and $20 \%$, respectively. A combination of forced ventilation and fogging system for cooling greenhouse was presented by Arbel et al. [14]. High pressure nozzles of more uniformity distribution coupled with fans placed at both ends were being the treatments imposed to achieve the required cooling demand. It was reported that air temperature and relative humidity of $28^{\circ} \mathrm{C}$ and $80 \%$, respectively were maintained during the summer at midday with the combination of forced ventilation and fogging.

\subsubsection{Roof Evaporation Cooling}

Roof evaporation cooling is sprinkling of water onto a surface of the roof so as to form a thin layer of the free water surface causing increase in the evaporation rate, and to fall to the wet bulb temperature of the closely surrounded air.

Cohen et al. [15] experimentally investigated the cooling efficiency of greenhouse by wetting the outer roof and inner crop soil crop soil surfaces where tomatoes were grown. They reported that wetting of roof had a smaller effect on reducing air and canopy temperature than wetting the canopy. However, combination of both wetting treatments reduced inside air temperature by about $5^{\circ} \mathrm{C}$ and canopy temperature by nearly $7^{\circ} \mathrm{C}$ below the ambient condition. Sutar and Tiwari studied the effect of flowing water film over the roof on greenhouse air temperature in a low cost plastic greenhouse of Delhi climatic conditions, India. They concluded that inside air temperature was observed to be $4^{\circ} \mathrm{C}-5^{\circ} \mathrm{C}$ lower than control greenhouse, however, when a shad cloth on the roof of the greenhouse was used with water film, inside air temperature drop was increased to $10^{\circ} \mathrm{C}$. Willits and Preet [17] conducted an experiment with intermittent application of water over externally mounted shad net on greenhouse. The results revealed that rise of greenhouse air temperature was reduced by $41 \%$ under wet cloth as compared to $18 \%$ under dry cloth.

\subsection{Shading}

The entry of unwanted radiation or light can be controlled by the use of shading. Shading does not allow impor- 
tant photo-synthetically active radiation (PAR), which is crucial for photosynthesis. However, it is a viable option for crop production during peak summer. Shading paints can be applied to the outside greenhouse cover with some degree of success but paints get washed away during the rainy season. Shade net application with different perforated mesh size and their evaluation with respect to local climate and region is necessary to get cooling benefits in summer. Ali et al. [18] developed an efficient greenhouse design for hot climatic conditions of Kuwait. Entry of solar radiation was allowed only from the roof of the even span greenhouse of $250 \mathrm{~m}^{2}$ floor area where tomatoes were grown. The roof was used during peak hours to control the inside air temperature. The results showed that combination of shading and fan and pad during peak summer maintained temperature of $30^{\circ} \mathrm{C}$ during the day and $22^{\circ} \mathrm{C}$ during night in greenhouse. Hu [19] experimentally investigated the cooling effect of external sun-shading. Two kinds of methods is tested: one is under the condition of closing the greenhouse, unfolding the external sun-shading to collect temperature and humidity date indoors and outdoors. Another one is to open the top window to ventilate to make the indoor and outdoor temperature and humidity in a relatively steady state, and then, unfold the external sun-shading and collect the temperature and humidity data indoors and outdoors. The result showed that, as the sun-radiation enhancing, temperature indoor presents a rise tendency, causing the effect of the external sun-shading, the humidity indoors and outdoors maintain 57\% basically. In the subsequent time, both of them present alternate change trend, but the difference is small.

\section{Conclusion}

Test and investigation are respectively conducted with these three cooling measures of natural ventilation, evaporate-cooling and shading cooling. There are some respectively differences among them. All of the methods have disadvantages and advantages. Choosing applicable and practical cooling methods depends on many aspects, such as local climate, agronomic condition, design and covering materials. To achieve desirable benefits, the combination of different cooling methods is necessarily used.

\section{References}

[1] Sethi, V.P. and Sharma, S.K. (2007) Experimental and Economic Study of a Greenhouse Thermal Control System Using Aquifer Water. Energy Conversion and Management, 48, 306-319. http://dx.doi.org/10.1016/j.enconman.2006.04.003

[2] Wang S.X. and Wang, X. (2009) Ventilation Rate of Various Vents in Plastic Covered Multi-Span Greenhouse. Transaction of the CSAE, 25, 248-251.

[3] Teitel, M. and Tanny, J. (1999) Natural Ventilation of Greenhouses: Experiments and Model. Agricultural and Forest Meteorology, 96, 59-71. http://dx.doi.org/10.1016/S0168-1923(99)00041-6

[4] Teitel, M., Liran, O., Tanny, J. and Barak, M. (2008) Wind Driven Ventilation of a Mono-Span Greenhouse with a Rose Crop and Continuous Screened Side Vents and Its Effect on Flow Patterns and Micro Climate. Biosystems Engineering, 101, 111-122. http://dx.doi.org/10.1016/j.biosystemseng.2008.05.012

[5] Teitel, M., Tanny, J. and Barak, M. (2007) Wind Driven Ventilation of a Mono-Span Greenhouse with a Rose Crop and Continuous Screened Side Vents and Its Effect on Flow Patterns and Micro Climate. Biosystems Engineering, 101, 111-122.

[6] Impron, I., Hemming, S. and Bot, G.P.A. (2007) Simple Greenhouse Climate Model as a Design Tool for Greenhouses in Tropical Low Land. Biosystems Engineering, 98, 79-89.

[7] Kozai, T. and Sase, S. (1978) A Simulation of Natural Ventilation for a Multi-Span Greenhouse. Acta Horticulturae, 87, 39-49. http://dx.doi.org/10.17660/actahortic.1978.87.3

[8] Landsberg, J.J., White, B. and Thorpe, M.R. (1979) Computer Analysis of the Efficacy of Evaporative Cooling for Glasshouse in High Energy Environments. Journal of Agricultural Engineering Research, 24, 29-39. http://dx.doi.org/10.1016/0021-8634(79)90058-1

[9] Chandra, P., Singh, J.K. and Majumdar, G. (1989) Some Results of Evaporative Cooling of a Plastic Greenhouse. Journal of Agricultural Engineering, 26, 274-280.

[10] Jain, D. and Tiwari, G.N. (2002) Modeling and Optimal Design of Evaporative Cooling System in Controlled Environment Greenhouse. Energy Conversion and Management, 43, 2235-2250. http://dx.doi.org/10.1016/S0196-8904(01)00151-0

[11] Ahmed, E.M., Abaas, O., Ahmed, M. and Ismail, M.R. (2011) Performance Evaluation of Three Different Types of Local Evaporative Cooling Pads in Greenhouses in Sudan. Saudi Journal of Biological Sciences, 18, 45-51. http://dx.doi.org/10.1016/j.sjbs.2010.09.005 
[12] Montero, J.I., Anton, A., Beil, A. and Franquet, C. (1994) Cooling of Greenhouse with Compressed air Fogging Nozzles. Acta Horticulturae, 281,199-209.

[13] Arbel, A., Yekutieli, O. and Barak, M. (1999) Performance of a Fog System for Cooling Greenhouses. Journal of Agricultural Engineering Research, 72,129-136. http://dx.doi.org/10.1006/jaer.1998.0351

[14] Arbel, A., Barak, M. and Shklyar, A. (2003) Combination of Forced Ventilation and Fogging Systems for Cooling Greenhouses. Biosystems Engineering, 84, 45-55. http://dx.doi.org/10.1016/S1537-5110(02)00216-7

[15] Cohen, Y., Stanhill, G. and Fuchs, M. (1983) An Experimental Comparison of Evaporative Cooling in a Naturally Ventilated Glasshouse Due to Wetting the Outer Roof and Inner Crop Soil Surfaces. Agricultural and Forest Meteorology, 28, 239-251. http://dx.doi.org/10.1016/0002-1571(83)90029-8

[16] Sutar. and Tiwari (1995) Analytical and Numerical Study of a Controlled Environment Agricultural System for Hot and Dry Climatic Conditions. Energy and Building, 23, 9-18. http://dx.doi.org/10.1016/0378-7788(95)00919-O

[17] Willits, D.H. and Preet, M.M. (2000) Intermittent Application of Water to an Externally Mounted Greenhouse Shade Cloth to an Modify Cooling Performance. Transactions of ASAE, 43, 1247-1252. http://dx.doi.org/10.13031/2013.3018

[18] Ali, H.M., Moustafa, S. and El-Mansy, H. (1990) An Efficient Greenhouse Design for Hot Climates. Energy Conversion Management, 30, 433-437. http://dx.doi.org/10.1016/0196-8904(90)90044-Y

[19] Hu, J. (2013) Experimental Research on Monomial Cooling Measure of Greenhouse in Summer. Smart Grid and Renewable Energy, 4, 48-52. http://dx.doi.org/10.4236/sgre.2013.41007 